\title{
BMJ Open Environmental and social benefits of the targeted intraoperative radiotherapy for breast cancer: data from UK TARGIT-A trial centres and two UK NHS hospitals offering TARGIT IORT
}

Nathan J Coombs, ${ }^{1}$ Joel M Coombs, ${ }^{2}$ Uma J Vaidya, ${ }^{3,4}$ Julian Singer, ${ }^{5}$ Max Bulsara, ${ }^{4,6}$ Jeffrey S Tobias, ${ }^{7}$ Frederik Wenz, ${ }^{8}$ David J Joseph, ${ }^{9}$ Douglas A Brown, ${ }^{10}$ Richard Rainsbury, ${ }^{11}$ Tim Davidson, ${ }^{12}$ Douglas J A Adamson, ${ }^{10}$ Samuele Massarut, ${ }^{13}$ David Morgan, ${ }^{14}$ Ingrid Potyka, ${ }^{4}$ Tammy Corica,,${ }^{4,9}$ Mary Falzon, ${ }^{15}$ Norman Williams, ${ }^{4}$ Michael Baum, ${ }^{4}$ Jayant S Vaidya ${ }^{4}$

To cite: Coombs NJ, Coombs JM, Vaidya UJ, et al. Environmental and social benefits of the targeted intraoperative radiotherapy for breast cancer: data from UK TARGIT-A trial centres and two UK NHS hospitals offering TARGIT IORT. BMJ Open 2016;6:e010703. doi:10.1136/bmjopen-2015010703

- Prepublication history and additional material is available. To view please visit the journal (http://dx.doi.org/ 10.1136/bmjopen-2015010703).

Received 30 November 2015 Revised 8 March 2016 Accepted 9 March 2016

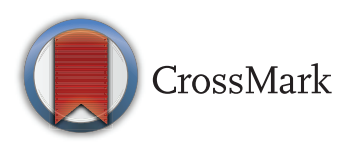

For numbered affiliations see end of article.

Correspondence to Professor Jayant S Vaidya; jayant.vaidya@ucl.ac.uk

\section{ABSTRACT}

Objective: To quantify the journeys and $\mathrm{CO}_{2}$ emissions if women with breast cancer are treated with risk-adapted single-dose targeted intraoperative radiotherapy (TARGIT) rather than several weeks' course of external beam whole breast radiotherapy (EBRT) treatment.

Setting: (1) TARGIT-A randomised clinical trial (ISRCTN34086741) which compared TARGIT with traditional EBRT and found similar breast cancer control, particularly when TARGIT was given simultaneously with lumpectomy, (2) 2 additional UK centres offering TARGIT.

Participants: 485 UK patients (249 TARGIT, 236 EBRT) in the prepathology stratum of TARGIT-A trial (where randomisation occurred before lumpectomy and TARGIT was delivered simultaneously with lumpectomy) for whom geographical data were available and 22 patients treated with TARGIT after completion of the TARGIT-A trial in 2 additional UK breast centres.

Outcome measures: The shortest total journey distance, time and $\mathrm{CO}_{2}$ emissions from home to hospital to receive all the fractions of radiotherapy. Methods: Distances, time and $\mathrm{CO}_{2}$ emissions were calculated using Google Maps and assuming a fuel efficiency of $40 \mathrm{mpg}$. The groups were compared using the Student $t$ test with unequal variance and the nonparametric Wilcoxon rank-sum (Mann-Whitney) test.

Results: TARGIT patients travelled significantly fewer miles: TARGIT 21 681, mean 87.1 (SE 19.1) versus EBRT 92 591, mean 392.3 (SE 30.2); had lower $\mathrm{CO}_{2}$ emissions $24.7 \mathrm{~kg}$ (SE 5.4) vs $111 \mathrm{~kg}$ (SE 8.6) and spent less time travelling: $3 \mathrm{~h}$ (SE 0.53 ) vs $14 \mathrm{~h}$ (SE 0.76 ), all $p<0.0001$. Patients treated with TARGIT in 2 hospitals in semirural locations were spared much longer journeys ( 753 miles, $30 \mathrm{~h}, 215 \mathrm{~kg} \mathrm{CO} 2$ per patient).

Conclusions: The use of TARGIT intraoperative radiotherapy for eligible patients with breast cancer

\section{Strengths and limitations of this study}

- This study calculated journeys made by patients with breast cancer to receive their radiotherapy, using the geographic and treatment data from a large randomised trial.

- The study then assessed the same outcomes (travel distances, travel time and $\mathrm{CO}_{2}$ emissions) in two semirural breast cancers-the results of this assessment confirm and reinforce the original results: the benefit of the use of TARGIT for patients from two semirural breast centres was even larger $(753$ miles $(1212 \mathrm{~km}), 30 \mathrm{~h}$, $215 \mathrm{~kg} \mathrm{CO}_{2}$ per patient).

- The carbon emissions were calculated from measured fuel economies in a standard family car in real-world driving conditions rather than relying on a car manufacturer's claimed emission figures that are derived under strict test conditions.

- Although the patients' addresses and address of the radiotherapy centre were known and used to calculate the journey, the exact daily travel for each patient was not available. However, this is unlikely to affect the results. Similarly, our estimates for carbon emissions assume a standard family car, so it may not be exact.

significantly reduces their journeys for treatment and has environmental benefits. If widely available, 5 million miles $(8000000 \mathrm{~km})$ of travel, 170000 woman-hours and 1200 tonnes of $\mathrm{CO}_{2}$ (a forest of 100 hectares) will be saved annually in the UK.

Trial registration number: ISRCTN34086741; Postresults.

\section{INTRODUCTION}

Awareness of the impact of climate change has led to increasing information being 
displayed about the carbon footprint of certain activities. For example, we are now more aware of the concept of 'food-miles' and the benefits of buying locally sourced products. With increasing centralisation of resources in healthcare, the trend is exactly the reverse of the trend to 'shop locally'. There is in fact a greater demand on patients and their families to travel to receive specialist treatment. $^{12}$

Numerous studies have assessed the impact of travel time and distance on a patient receiving healthcare or choosing treatment options. ${ }^{3}{ }^{4}$ In some international studies, patients who had to travel many miles for radiotherapy after breast cancer treatment chose a mastectomy rather than breast conservation ${ }^{5-7}$ and multiple fractions of whole breast radiotherapy, but this was not seen in some UK studies. ${ }^{3} 8$ Similarly, the uptake of chemotherapy or postmastectomy radiotherapy may be lower in rural communities where travel to a radiotherapy centre is difficult. ${ }^{9} 10$ The daily travel for patients and their relatives will often affect their quality of life and impact on them and their family members. ${ }^{1}{ }^{2}$

The management of breast cancer has changed over the decades. However, the requirement of patients to travel to receive these specialist services is often forgotten by policymakers. ${ }^{11}$ Conventionally, patients who have breast cancer and breast-conserving surgery are recommended to receive whole breast external beam radiotherapy (EBRT) daily, over 3-6 weeks following surgery.

Current UK provision of radiotherapy within the National Health Service (NHS) is based in 62 hospital sites (figure 1): England-52, Scotland-5, Wales-3 and Northern Ireland-2. ${ }^{12}$ The National Radiotherapy Advisory Group recommends that travel times should be less than $45 \mathrm{~min}$ for the majority of patients as this is known to impact on access and uptake. ${ }^{13}$ The red dots in figure 1 show a radius of 13 miles $(21 \mathrm{~km})$, which is the average distance of a patient from the radiotherapy centre in the TARGIT-A trial, thus showing how large areas remain outside these perimeters. Accounting for the population density, we have estimated that two-thirds of the UK population lives more than 13 miles from a radiotherapy centre (figure 1 and supplementary table 2). ${ }^{28}$

Approaches such as the use of risk-adapted targeted intraoperative radiotherapy (TARGIT IORT) ${ }^{14}{ }^{15} \mathrm{can}$ obviate the need for whole breast EBRT in selected patients. ${ }^{16}{ }^{17}$ Indeed, single-dose TARGIT IORT is now offered routinely as a treatment option in many other countries. ${ }^{18}$

The TARGIT-A trial was an international randomised controlled trial initiated in the UK that showed that a single dose of IORT using the Intrabeam device (Carl Zeiss) was not inferior to traditional EBRT in local control after breast-conserving surgery. ${ }^{17}$ This delivers a single fraction of radiotherapy (20 gy) into the tumour cavity and adds about $20-40 \mathrm{~min}$ to the operative procedure. UK centres contributed $20 \%$ of the 3451 patients recruited in the TARGIT-A trial from 33 centres in 11 countries worldwide.

This study compares the travel implications and journey times within each randomised treatment group of the TARGIT-A trial in the UK.

We also measured the impact of introducing TARGIT IORT in two UK breast centres without on-site radiotherapy and assessed the likely environmental gains to be made by implementing TARGIT IORT in the management of early breast cancer in the UK.

\section{METHODS}

\section{TARGIT-A trial data}

Geographic and radiotherapy data from the UK patients who had been recruited into the TARGIT-A randomised controlled trial were assessed. In six UK hospitals (University College London, Royal Free, Whittington, Guy's and St Thomas' (all in London), Ninewells (in Dundee, Scotland) and Royal Hampshire County (in Winchester)), the patients undergoing breast-conserving surgery either received traditional EBRT or were selected to receive TARGIT IORT as a single dose using the Intrabeam device (Carl Zeiss). Patients who received TARGIT were recommended additional breast EBRT (without a tumour bed boost) if their final tumour histology had prespecified adverse prognostic factors. Fifteen per cent to $20 \%$ of patients randomly allocated to receive TARGIT were expected to receive additional EBRT. Supported by the results of the TARGIT-A trial, ${ }^{17}$ the preferred method of using TARGIT is during initial lumpectomy, and therefore, for this paper, we restricted the analysis to the prepathology stratum of the TARGIT-A trial.

For each patient, we first calculated the shortest driving distance from home to the radiotherapy centre and travel time (excluding traffic delays) using Google Maps. We then calculated the total distance travelled and total journey time to receive all of the recorded fractions of radiotherapy for each patient. We assumed that patients who received EBRT required two additional journeys, for consent and for radiotherapy planning. Typically, a patient receiving 15 fractions of EBRT (3 weeks of radiotherapy) would attend the radiotherapy centre on at least 17 occasions. Amongst patients selected to have EBRT, those who lived a considerable distance from a TARGIT trial centre (more than 60 miles, $100 \mathrm{~km}$ ) were excluded from the analysis $(\mathrm{n}=7)$ as they may have chosen to travel to a local radiotherapy centre closer to their home. A comparison was made between the aggregate distance and travel times between the two treatment arms (TARGIT vs EBRT) and between TARGIT-A trial centres in London, Winchester and Dundee.

\section{Swindon and Harlow patients}

In 2014, two UK breast centres without on-site radiotherapy units (in Swindon and Harlow) started using 
Figure 1 Map of the UK showing the locations of radiotherapy centres with a radius of 13 miles $(20 \mathrm{~km})$ drawn around them. Two-thirds $(63 \%)$ of the UK population live outside of towns that have a radiotherapy centre (data given in online supplementary table S2). Contains OS data $\odot$ Crown copyright 2016, and reference 28 .

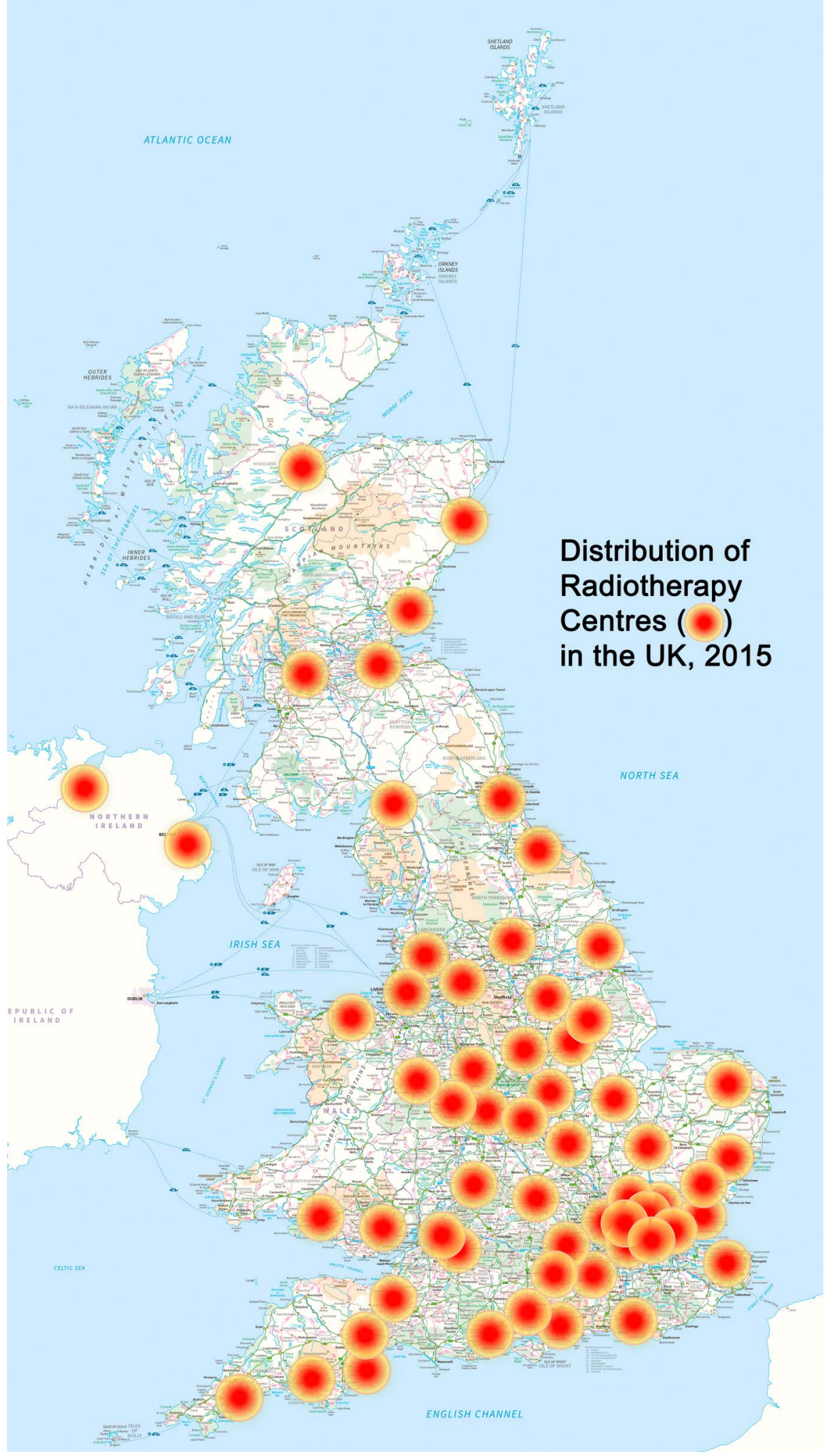

TARGIT IORT. Using the patient's postcode and Google Maps, the distance that each of the 22 patients would have driven to their local radiotherapy centres (Oxford, Bath, North Middlesex or Cambridge) was calculated.

To assess the impact of travelling to a radiotherapy centre from his own hospital, the first author (NJC) undertook six return journeys from Swindon to Oxford and from Swindon to Bath using a medium-sized family car (a 7-year-old car with a $1.9 \mathrm{~L}$ diesel engine) in normal driving conditions, during a weekday and outside of peak times, and measured the actual distance travelled, time taken and fuel used. The estimates using Google maps were found to be an accurate reflection of such journeys (see online supplementary table S1). 
Therefore, for each patient with breast cancer treated with lumpectomy and TARGIT, we could estimate these values for travelling between their home and the radiotherapy centre using Google maps. We estimated the total travel distance assuming a standard 3-week course of radiation for the 22 patients who received TARGIT IORT mainly as part of training for participation in the TARGIT-B trial (http://www.nets.nihr.ac.uk/projects/ hta/1010407, http://goo.gl/sgdcTr) in the past 15 months.

\section{Estimation of $\mathrm{CO}_{2}$ emission}

We estimated the carbon dioxide produced by private transport based on the following measurement and assumptions: the fuel economy of the car was 39.7 miles per gallon (mpg; 6.961/100 km), public transport usage was negligible, and half of the cars used diesel as a fuel and half used petrol. The $\mathrm{CO}_{2}$ produced by a $40 \mathrm{mpg}$ diesel car is $299 \mathrm{~g} / \mathrm{mile}(186 \mathrm{~g} / \mathrm{km})$ and that produced by a $40 \mathrm{mpg}$ petrol car is $272 \mathrm{~g} / \mathrm{mile}(169 \mathrm{~g} / \mathrm{km}){ }^{19}$

\section{Statistical analysis}

The null hypothesis was no difference in travelling distance or time between the two randomised groups. For statistical analyses, given that the distances travelled were skewed (not normally distributed) for at least one of the randomisation arms (TARGIT), we used both the Student $\mathrm{t}$ test with unequal variance as well as the nonparametric Wilcoxon rank-sum (Mann-Whitney) test. We used Microsoft Excel and STATA V.14.0 for statistical analysis.

\section{RESULTS}

\section{TARGIT-A trial data}

Between 1999 and 2012, 714 patients were recruited to the UK centres for the TARGIT-A trial, and of these, 568 were in the prepathology stratum. Those patients randomised to receive TARGIT had their radiotherapy at the time of their primary surgery. Eighty-three patients (TARGIT 50, EBRT 33) were excluded from analysis due to insufficient $(n=70)$ or inaccurate $(n=6)$ home postcode details, or where the patient would have travelled to a closer radiotherapy centre to receive EBRT ( $\mathrm{n}=7)$, leaving $485(85.4 \%)$ for data analysis. Of these, 236 patients $(48.7 \%)$ had been randomised to receive EBRT. In the 249 patients who had been randomised to receive TARGIT, $46(18.5 \%)$ received additional EBRT.

\section{Travel distance}

Overall, these 485 UK patients would have travelled 114273 miles (183905 km; TARGIT 21681 (34 $892 \mathrm{~km})$ versus EBRT $92591(149011 \mathrm{~km}))$ for planning, consent and receiving radiotherapy as part of the TARGIT-A trial, with those in the TARGIT arm travelling considerably less than those in the EBRT arm (mean distance driven in miles: TARGIT 87.1 (SE 19.1) versus
EBRT 392.3 (SE 30.2), in kilometres: TARGIT 140.2 (SE 30.7) versus EBRT 631.4 (SE 48.6), $\quad \mathrm{p}<0.0001$ Wilcoxon rank-sum test, and $\mathrm{p}<0.0001$ with the Student $\mathrm{t}$ test assuming unequal variance). Thus, the patients in the TARGIT arm were saved, on average, a travel distance of 305.2 miles (SE 35.8; $491.2 \mathrm{~km}$ (SE 57.6)). The difference in travelling distance was more pronounced for patients in Dundee (TARGIT 123.9 miles (SE 44.2) vs EBRT 647.4 miles (SE 55.2), TARGIT $199.4 \mathrm{~km}$ (SE 71.1 ) vs EBRT $1041.9 \mathrm{~km}$ (SE 88.8)), reflecting its rural surroundings where, on average, each patient saved themselves a journey of 523.5 miles (SE 70.7), $842.5 \mathrm{~km}$ (SE 113.8; figure 2 top)

\section{$\mathrm{CO}_{2}$ emission}

We estimate the total $\mathrm{CO}_{2}$ emissions by UK patients in the prepathology stratum of the TARGIT-A trial to be 32.5 tonnes, of which $81 \%$ (26.3 tonnes) was contributed by patients in the EBRT arm. The TARGIT arm contributed $19 \%$ of the total $\mathrm{CO}_{2}$ (6.2 tonnes), which corresponds to the fact that $18.5 \%$ of these patients received additional EBRT. The mean $\mathrm{CO}_{2}$ emissions for each patient in the EBRT arm was $111.4 \mathrm{~kg}$ (SE 8.6), whereas the mean emission by those randomised to TARGIT was $24.7 \mathrm{~kg}$ (SE 5.4), $\mathrm{p}<0.0001$; a reduction of $86.7 \mathrm{~kg}$ (SE 10.2) per patient. A much larger reduction in emissions by being in the TARGIT arm was seen in the patients treated in Dundee, reflecting the greater
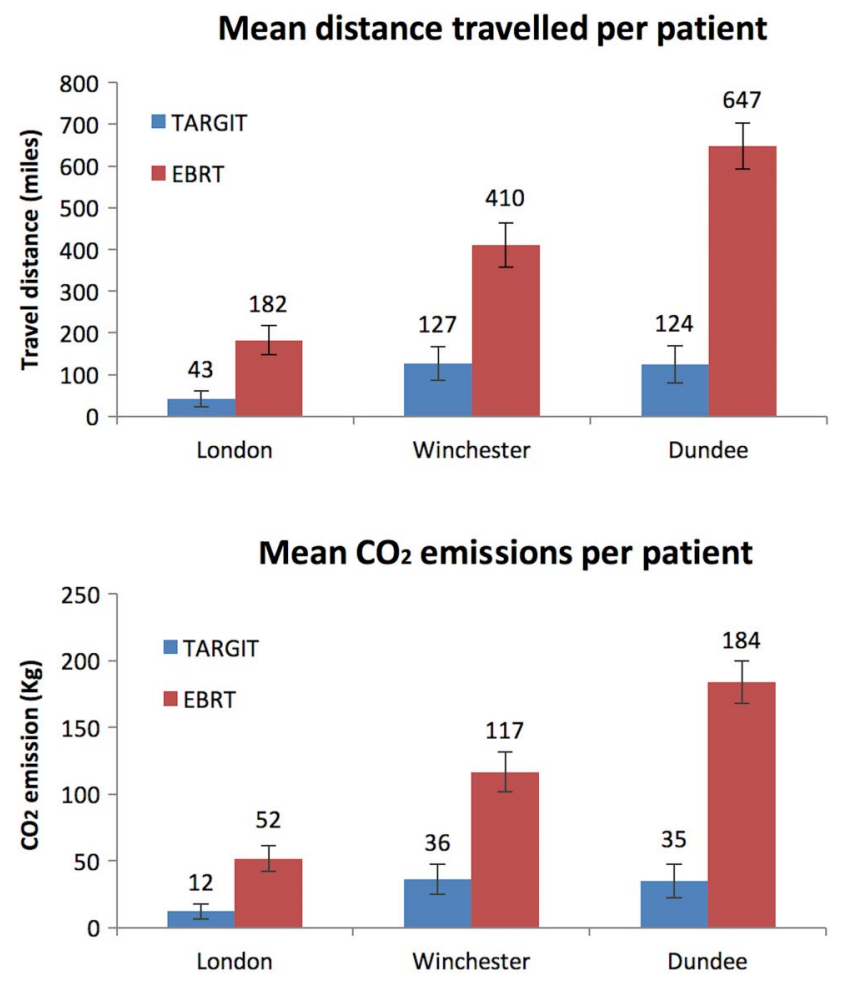

Figure 2 The mean distance travelled (above) and $\mathrm{CO}_{2}$ emissions (below) per patient for the allocated treatment. The error bars show the SE of the mean. (1 mile=1.61 km). EBRT, external beam whole breast radiotherapy. 
distance travelled by these patients. The mean $\mathrm{CO}_{2}$ emission for Dundee patients randomised to receive TARGIT was $35 \mathrm{~kg}$ (SE 12.5) compared with $184 \mathrm{~kg}$ (SE 15.7) for EBRT patients, a saving of $149 \mathrm{~kg}$ (SE 20.1) of $\mathrm{CO}_{2}$ (figure 2 bottom).

\section{Travel time}

Overall, the mean time taken to travel for radiotherapy was $3.0 \mathrm{~h}$ (SE 0.53) for those randomised to TARGIT versus $14.0 \mathrm{~h}$ (SE 0.76) for EBRT, an average saving of $11 \mathrm{~h}$ (SE 0.92). The saving was longer for Dundee patients, at 14.2 h (SE 1.6). This does not include time spent in traffic jams, finding a parking space, waiting for the turn to receive the radiation dose, or actually receiving the fraction of radiotherapy. Of the 249 patients in the TARGIT arm, $81.5 \% \quad(n=203)$ patients had received TARGIT IORT during lumpectomy and required no further travel for radiotherapy. The 46 patients who received additional EBRT travelled similar distances with similar journey times as those receiving traditional EBRT. Figure 3 shows the time taken to travel for radiotherapy in the three cities. Note that although the distances in London were shorter (figure 2), the time for travel for EBRT was relatively longer because of lower average speeds achievable in the city.

\section{Swindon and Harlow patients}

In the past 15 months (July 2014 to September 2015), the first 22 patients who received TARGIT IORT in Swindon $(\mathrm{n}=7)$ and Harlow $(\mathrm{n}=15)$ saved, on average, 753 miles (median 717, range 129-1751 miles; $1212 \mathrm{~km}$ (median 1154, range 208-2818 km)) of travel. Patients treated in Swindon would have travelled farther for EBRT than those in Harlow (1014 (SE 224) vs 631 (SE 130) miles per patient (1632 (SE 361) vs 1016 (SE 209) kilometres per patient); figure 4). These 22 patients would have driven a total distance of 16572 miles $(26664 \mathrm{~km})$ if they had received traditional EBRT. A total of 4.73 tonnes of $\mathrm{CO}_{2}$ would have been produced by these car journeys $(215 \mathrm{~kg} /$ patient $)$. Each Swindon patient saved approximately $30.9 \mathrm{~h}$ (SE 3.3) of travelling time with mean journey times of $1 \mathrm{~h} 50 \mathrm{~min}$ each day (median $1 \mathrm{~h} 52 \mathrm{~min}$, range $1 \mathrm{~h} 4 \mathrm{~min}-2 \mathrm{~h} 28 \mathrm{~min}$ ).

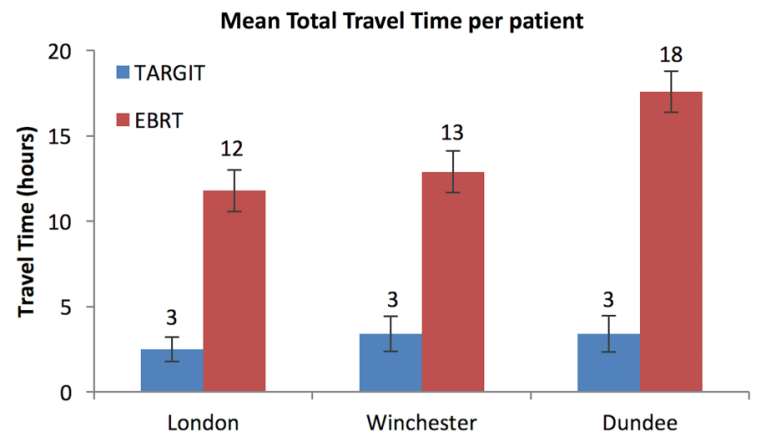

Figure 3 Mean time travelled by a patient for each allocated treatment. EBRT, external beam whole breast radiotherapy.
Travel saved by each patient by taking TARGIT IORT

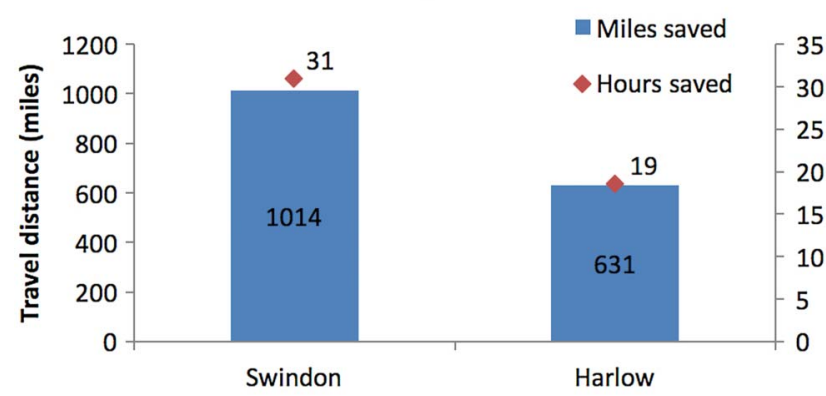

Figure 4 Estimated travel that was saved by patients in Swindon and Harlow because they were treated with TARGIT IORT (1 mile=1.61 km).

Harlow patients saved $18.5 \mathrm{~h}$ (SE 1.9) of journey times with mean daily return journey times of $1 \mathrm{~h} 6 \mathrm{~min}$ (median $19 \mathrm{~h}$, range $28 \mathrm{~min}-1 \mathrm{~h} 38 \mathrm{~min}$ ).

\section{DISCUSSION}

We found that within the TARGIT-A trial, UK patients in the prepathology stratum randomised to TARGIT saved themselves from travelling 305 miles $(491 \mathrm{~km})$ for $11 \mathrm{~h}$ and avoided $\mathrm{CO}_{2}$ emissions of $86 \mathrm{Kg}$. In the context of routine clinical practice in two hospitals outside of London, the saving per patient was much larger in terms of distance: 753 miles $(1212 \mathrm{~km}), \mathrm{CO}_{2}$ emissions $-215 \mathrm{~kg} \mathrm{CO}_{2}$ and time-between 19 and $31 \mathrm{~h}$. Of course, we have not taken into account the actual psychological distress that may also be reduced.

This study is a detailed analysis of the distance travelled by UK patients within a large randomised international study. Use of the patient's postcode allowed accurate journey distances to be calculated and, by using UK-wide data from patients treated in four geographical centres, this allowed for a comparison of the travel implications for patients within an urban or semirural setting. The predicted travel times according to Google Maps were very close to the measured index journeys taken by the author. However, these journeys are likely to be an underestimate of actual times taken by patients as these cannot take into account any delays due to traffic or parking problems.

The medical literature contains few studies about the implications for patients and their families in travelling to receive radiotherapy. Our data are consistent with the one UK published study that showed that some patients were travelling up to 60 miles in each direction. ${ }^{1}$

\section{Estimation of impact on UK patients with breast cancer}

In the UK, over 50000 new breast cancers are diagnosed each year, ${ }^{20}$ of which approximately $75 \%$ receive breastconserving surgery ${ }^{21} 22$ and, depending on the definition of suitability of patients for IORT as a treatment modality (ASTRO, ESTRO or TARGIT criteria ${ }^{23-25}$ ), $15.8 \%, 34.1 \%$ or $54 \%$ of these patients could be 
offered single-dose TARGIT IORT. If this treatment was offered in the UK and established patient selection criteria applied, either 592512800 or 20250 may be saved many weeks of travel to receive EBRT. Using the very conservative estimate of travelling distance (provided by the TARGIT study patients), we estimate that this could save $1.8,3.9$ or 6.2 million miles of journeys and reduce $\mathrm{UK} \mathrm{CO}_{2}$ emissions by between 516 and 1763 tonnes annually (table 1 ). It seems to us that a conservative estimate is 5 million miles of journey saved per year, that is, about 100 miles per breast cancer case diagnosed.

It should be noted that early in the course of the TARGIT-A trial, most UK radiotherapy departments began to adopt the 3-week regimes rather than 6-week regimes, so the average number of fractions of radiation received by the trial patients was 17.5 . The current provision of radiotherapy is concentrated in the larger hospitals in urban centres, so patients could face either a daily prolonged 'cross-city commute' or a longer journey from surrounding towns or villages. The geographical location of many moderate-sized UK breast centres is such that patients need to travel considerable distances to receive radiotherapy, and we need to remember that the potential environmental and economic savings of introducing TARGIT may be greater when applied to a breast cancer population outside of large UK urban centres.

These figures are likely to be an underestimate of the $\mathrm{CO}_{2}$ reductions as applied in the $\mathrm{UK}$, as we have not taken into account traffic conditions. Similarly, the savings in travel times, mileage and $\mathrm{CO}_{2}$ for patients is likely to be even greater as many UK breast units do not have an on-site radiotherapy centre, as is the case with two of the six TARGIT-A trial centres (Whittington and Winchester) that required their patients to travel to a different hospital for EBRT. Typically, most UK patients, just as the patients treated in Swindon or Harlow, would thus travel more than twice the distance of their
TARGIT study counterparts (753 vs 305 miles; 1212 vs $491 \mathrm{~km})$.

Carbon sequestration by woodland is often promoted to offset carbon production. Depending on tree species, the annual rate of carbon absorption for UK forests is 25 tonnes/hectare. ${ }^{26}$ One tonne of carbon is contained within 3.67 tonnes of $\mathrm{CO}_{2}$. Using a figure of 3 tonnes/ hectare per year, we estimate that failing to introduce TARGIT in the UK would require continuous maintenance of an area of mature forest over an area of 47-395 hectares to offset the $\mathrm{CO}_{2}$ produced by travel of these selected patients to receive radiotherapy. This forest would need to cover St Jame's Park (23ha), Green Park (19ha), Buckingham Palace Gardens (17ha), Kensington Gardens (111Ha) and Hyde Park (142ha) combined.

The use of public transportation or bicycles and walking, particularly in London, may change these calculations of the carbon footprint. However, the vast majority of patients in the rest of the country would have used a car for which these calculations are valid.

As clinicians, we need to remember the impact of our prescribed therapies on patients and their relatives. In rural areas, chemotherapy services may be provided closer to the patient's home to reduce the need to travel, and indeed, breast screening is usually available using mobile units. However, the need to travel to receive radiotherapy has an environmental impact that, until now, has been ignored. We have demonstrated that providing single-dose TARGIT treatment to selected UK patients with breast cancer will benefit patient travel times and $\mathrm{CO}_{2}$ emissions. Given that patients with breast cancer constitute about a third of patients in a radiotherapy department, this should also reduce the traffic congestion around the hospital.

This is the first study to quantify the environmental benefit of introducing TARGIT IORT and demonstrates the magnitude of the impact on our environment of

Table 1 Estimate of annual number of UK patients with breast cancer suitable for IORT, travel distances saved and reduction in $\mathrm{CO}_{2}$ emissions ( 1 mile $=1.61 \mathrm{~km}$ )

\begin{tabular}{|c|c|c|c|c|c|}
\hline Selection criteria & $\begin{array}{l}\text { Proportion } \\
\text { of UK } \\
\text { patients (\%) }\end{array}$ & $\begin{array}{l}\text { Annual UK } \\
\text { patients suitable } \\
\text { for TARGIT- } \\
\text { Alone }\end{array}$ & $\begin{array}{l}\text { Travel distance saved } \\
\text { (million miles) } \\
305 \text { mile/pt* or } \\
753 \text { miles/pt } †\end{array}$ & $\begin{array}{l}\mathrm{CO}_{2} \\
\text { emissions } \\
\text { saved (tonnes) }\end{array}$ & $\begin{array}{l}\text { Area of forest to } \\
\text { sequester annual } \\
\mathrm{CO}_{2} \text { emissions } ¥ \text { (ha) }\end{array}$ \\
\hline \multirow[t]{2}{*}{ ASTRO§ } & 15.8 & 5925 & $1.81^{\star}$ & $516^{*}$ & $46.9^{\star}$ \\
\hline & & & $4.46 \dagger$ & $1274 \dagger$ & $115.7 \dagger$ \\
\hline \multirow[t]{2}{*}{ ESTRO§ } & 34.1 & 12800 & $3.90^{*}$ & $1115^{*}$ & $101.2^{*}$ \\
\hline & & & $9.64 \dagger$ & $2752 \dagger$ & 249.9† \\
\hline \multirow[t]{2}{*}{ TARGITף } & 54 & 20250 & $6.18^{\star}$ & $1763^{*}$ & $160.2^{*}$ \\
\hline & & & $15.25 \dagger$ & 4353† & $395.4 †$ \\
\hline
\end{tabular}

${ }^{*}$ Estimate as per TARGIT-A trial patients.

†Estimate as per Swindon and Harlow patients.

$\ddagger$ Calculated using a value of three tonnes carbon sequestered per hectare per annum. $\S B$ ased on consensus opinion only. ${ }^{23} 24$

IBased on randomised evidence (TARGIT-A trial) and two large cohort studies (French and German). ${ }^{17} 25$

IORT, intraoperative radiotherapy. 
asking our patients to travel to receive centralised radiotherapy services. The analysis and concepts described are applicable in every aspect of healthcare where a patient is required to travel to receive a series of treatments. While the term 'food-miles' has become commonplace in the mindset of the general public, perhaps the concept of 'therapy-miles' ought to be considered when planning and prescribing patient treatment.

Our finding of a saving of about 87 to $215 \mathrm{~kg} \mathrm{CO}_{2}$ emissions for each patient receiving TARGIT (and thus from making TARGIT available to every patient with breast cancer having a lumpectomy in the NHS) is considerably greater than the estimated savings of the study investigating the benefits of introducing a different mode of improving access to services, namely, mobile breast screening units, which is about $1.25 \mathrm{~kg} \mathrm{CO}_{2}$ per woman screened. ${ }^{27}$

We conclude that introducing TARGIT as an option for appropriate patients in the UK will contribute significantly to saving patients time, cost, fuel and $\mathrm{CO}_{2}$ emissions.

\section{Author affiliations}

${ }^{1}$ Department of Breast Surgery, Great Western Hospital, UK

${ }^{2}$ Royal Wootton Bassett Academy, UK

${ }^{3}$ Nonsuch High School for Girls, UK

${ }^{4}$ Surgical and Interventional Trials Unit of the Division of Surgery and Interventional Science, University College London, London, UK

${ }^{5}$ Department of Radiotherapy, Princess Alexandra Hospital, Harlow, UK

${ }^{6}$ University of Notre Dame, Fremantle, Western Australia, Australia

${ }^{7}$ Department of Radiation Oncology(JST), University College London, London, UK

${ }^{8}$ Department of Radiation Oncology, University of Heidelberg, Germany

${ }^{9}$ Department of Radiation Oncology, Sir Charles Gairdner Hospital, Nedlands, Western Australia, Australia

${ }^{10}$ Ninewells Hospital, Dundee, UK

${ }^{11}$ Royal Hampshire County Hospital, Winchester, UK

${ }^{12}$ Royal Free Hospital, London, UK

${ }^{13}$ Centro di Riferimento Oncologica, Aviano, Italy

${ }^{14}$ Sherwood Forest Hospitals NHS Foundation Trust, Nottinghamshire, UK

${ }^{15}$ Department of Pathology, University College London, London, UK

Twitter Follow Jayant Vaidya at @jsvaidya

Acknowledgements The authors are grateful to Mr Andrew Binmore, BSc (Hons), Forestry Dip.Th, for his advice and analysis of the tree physiology and carbon sequestration data in UK forestry and to Mr Stephen Foulds for his programming skills.

Contributors NJC, JMC, UJV, JS, MaB, DB, RR, TD, DJAA, IP, NW, JST, MiB and JSV were involved in the conception, design, data collection and analysis, manuscript writing and final approval. FW, DJ, DM, TC and MF were involved in discussion, manuscript writing and final approval.

Funding The TARGIT-A trial was supported by University College London Hospitals (UCLH)/UCL Comprehensive Biomedical Research Centre, UCLH Charities, National Institute for Health Research Health Technology Assessment programme, Ninewells Cancer Campaign, National Health and Medical Research Council, and German Federal Ministry of Education and Research.

Competing interests NJC, JMC, MiB, JST, FW, DJ, TC, MF, IP, NW and JSV declare the cost of travelling to some meetings where TARGIT treatment is discussed, from Carl Zeiss, the manufacturer of Intrabeam. JSV declares honoraria when speaking about TARGIT at some meetings.

Provenance and peer review Not commissioned; externally peer reviewed.

Data sharing statement No additional data are available.

Open Access This is an Open Access article distributed in accordance with the terms of the Creative Commons Attribution (CC BY 4.0) license, which permits others to distribute, remix, adapt and build upon this work, for commercial use, provided the original work is properly cited. See: http:// creativecommons.org/licenses/by/4.0/

\section{REFERENCES}

1. Junor EJ, Macbeth FR, Barrett A. An audit of travel and waiting times for outpatient radiotherapy. Clin/ Oncol 1992;4:174-6.

2. Fitch MI, Gray RE, McGowan T, et al. Travelling for radiation cancer treatment: patient perspectives. Psychooncology 2003;12:664-74.

3. Jones AP, Haynes R, Sauerzapf V, et al. Travel time to hospital and treatment for breast, colon, rectum, lung, ovary and prostate cancer. Eur J Cancer 2008;44:992-9.

4. Guidry JJ, Aday LA, Zhang D, et al. Transportation as a barrier to cancer treatment. Cancer Pract 1997;5:361-6.

5. Lam J, Cook T, Foster S, et al. Examining determinants of Radiotherapy access: do cost and radiotherapy inconvenience affect uptake of breast-conserving treatment for early breast cancer. Clin Oncol 2015;27:465-71.

6. Goyal S, Chandwani S, Haffty BG, et al. Effect of travel distance and time to radiotherapy on likelihood of receiving mastectomy. Ann Surg Oncol 2015;22:1095-101

7. Gollop SJ, Kyle SM, Fancourt MWE, et al. Why Taranaki women choose to have a mastectomy when suitable for breast conservation treatment. ANZ J Surg 2009;79:604-9.

8. Sauerzapf VA, Jones AP, Haynes R, et al. Travel time to radiotherapy and uptake of breast-conserving surgery for early stage cancer in Northern England. Health Place 2008;14:424-33.

9. Lin CC, Bruinooge SS, Kirkwood MK, et al. Association between geographic access to cancer car, insurance, and receipt of chemotherapy: geographic distribution of oncologists and travel distance. J Clin Oncol 2015;33:3177-85.

10. Punglia RS, Weeks JC, Neville BA, et al. Effect of distance to radiation treatment facility on use of radiation therapy after mastectomy in elderly women. Int $J$ Radiat Oncol Biol Phys 2006;66:56-63.

11. Longo CJ, Fitch M, Deber RB, et al. Financial and family burden associated with cancer treatment in Ontario, Canada. Support Cancer Care 2006;14:1077-85.

12. Barkworth A. Census of the Radiotherapy Radiographic Workforce in the UK, 2015. s.I. Society of Radiographers, 2015. ISBN: 978-909802-06-3.

13. National Radiotherapy Advisory Group. 2013. http:// www.england. nhs.uk/wp-content/uploads/2013/06/b01-radiotherapy.pdf

14. Vaidya JS, Baum M, Tobias JS, et al. The novel technique of delivering targeted intraoperative radiotherapy (Targit) for early stage breast cancer. Eur J Surg Oncol 2002;28:447-54.

15. Vaidya JS, Baum M, Tobias JS, et al. Targeted intra-operative radiotherapy (Targit): an innovative method of treatment for early breast cancer. Ann Oncol 2001;12:1075-80.

16. Vaidya JS, Joseph DJ, Tobias JS, et al. Targeted intraoperative radiotherapy versus whole breast radiotherapy for breast cancer (TARGIT-A trial): an international, prospective, randomised, non-inferiority phase 3 trial. Lancet 2010;376:91-102.

17. Vaidya JS, Wenz F, Bulsara M. Risk-adapted targeted intra-operative radiotherapy versus whole-breast radiotherapy for breast cancer: 5 -year results for local control and overall survival from the TARGIT-A randomised trial. Lancet 2014;383:603-13.

18. Hawkes N. Start of cheaper technique for breast cancer is delayed in UK despite adoption elsewhere. BMJ 2015;350:h2874.

19. ETA. Calculating a car's CO2 emissions from its mpg. eta.co.uk. [Online] February 22, 2010 (cited 28 August 2015). http://www.eta. co.uk/2010/02/22/calculating-a-cars-co2-emissions-from-its-mpg/.

20. Office for National Statistics. Cancer Statistics Registrations; registrations of cancers diagnosed in 2013. England: Office for National Statsitics, 2015.

21. Caldon LJM, Collins KA, Wilde DJ, et al. Why do hospital mastectomy rates vary? Differences in the decision-making experiences of women with breast cancer. $\mathrm{Br} \mathrm{J}$ Cancer 2011;104:1551-7. 
22. Jeevan R, Cromwell DA, Trivella M, et al. Reoperation rates after breast conserving surgery for breast cancer among women in England: retrospective study of hospital episode statistics. BMJ 2012;345:e4505.

23. Smith BD, Arthur DW, Buchholz TA, et al. Accelerated partial breast irradiation consensus statement from the American society for radiation oncology (ASTRO). Int J Radiat Oncol Biol Phys 2009;74:987-1001.

24. Polgár C, Van Limbergen E, Pötter R, et al, GEC-ESTRO breast cancer working group. Patient selection for accelerated partial-breast irradiation (APBI) after breast-conserving surgery: recommendations of the groupe européen de curie thérapie-european society for therapeutic radiology and oncology (GEC-ESTRO) breast cancer working group based on clinical evidence (2009). Radiother Oncol 2010:94:264-73.

25. Sperk E, Astor D, Keller A, et al. A cohort analysis to identify eligible patients for intraoperative radiotherapy (IORT) of early breast cancer. Radiat Oncol 2014;9:154.

26. Dewer RC, Cannell MGD. Carbon sequestration in the trees, products and soils of forest. Tree Physiol 1992;11:49-71.

27. Bond A, Jones A, Haynes R, et al. Tackling climate change close to home: mobile breast screening as a model. J Health Serv Res Policy 2009;14:165-7.

28. Office for National Statistics. Population Census 2011. 2011 (cited 15 April 2015). http://www.ons.gov.uk/ons/taxonomy/index.html? nscl=Population 